\title{
Optimization of equilibrium headspace analysis of volatile flavor compounds of Malaysian soursop (Annona muricata): Comprehensive two-dimensional gas chromatography time-of-flight mass spectrometry.
}

\begin{abstract}
Headspace solid-phase microextraction (HS-SPME) coupled to comprehensive twodimensional gas chromatography time-of-flight mass spectrometry (GC $\times$ GC-TOFMS) was applied for equilibrium headspace analysis of Malaysian soursop (Annona muricata) volatile flavor compounds. A two-level fractional factorial design (25-1) was used to determine the effect of SPME variables, namely, SPME fibers, adsorption temperature, extraction time, amount of salt, sample amount and sample concentration on the extraction efficiency of volatile flavor compounds. A total of 37 volatile compounds were identified, comprising 21 esters, 6 alcohols, 3 terpenes, 2 acids, 2 ketones, 2 aldehydes and an aromatic with different hydrophobicities $(\log \mathrm{P})$ ranging between -0.14 and 4.83 . Extraction using $10 \mathrm{~g}$ of diluted $(5 \% \mathrm{w} / \mathrm{w})$ blended soursop pulp with CAR/PDMS fiber at $25{ }^{\circ} \mathrm{C}$ for $30 \mathrm{~min}$ and $30 \%(\mathrm{w} / \mathrm{w})$ of $\mathrm{NaCl}$ under stirring mode resulted in the highest extraction efficiency of volatile flavor compounds. The principal component analysis score discriminated the influence of SPME variables on the equilibrium headspace concentration of target volatile compounds.
\end{abstract}

Keyword: Headspace solid-phase microextraction; Two-dimensional gas chromatography; Time-of-flight mass spectrometry; Equilibrium headspace analysis; Soursop. 